\title{
El referéndum. Concepto general y regulación legal en el Perú
}

\author{
Hubert Wieland Conroy
}

\section{Introducción}

La institución del referéndum aparece en el constitucionalismo peruano de forma expresa recién en la Constitución de 1993. Figura en la Carta vigente como derecho fundamental de los ciudadanos en el inciso $17 \mathrm{del}$ artículo 2, como derecho político en el artículo 31, en ambos casos del Título I —De la Persona y de la Sociedad, y como derecho administrativo en artículo 190, relativo a asuntos de descentralización y demarcación regional. Por otro lado, aparece también como una facultad del Congreso de la República en el marco de los procedimientos previstos para efectuar reformas constitucionales en el artículo 206 del Título VI- De la Reforma de la Constitución.

Sin embargo, el concepto de referéndum tiene dos sentidos en la Constitución vigente. El primero tiene que ver con el carácter ratificatorio de un acto normativo, tal como en el caso de una reforma constitucional, de la aprobación de una norma con rango de ley y una de ordenanza municipal. Los órganos competentes aprueban la norma y la ciudadanía las ratifica, ya sea por iniciativa propia o a instancia del órgano involucrado como es el caso del Congreso de la República en materia de reformas constitucionales. El segundo tiene un carácter distinto, ya que su objeto no es ratificar una norma sino, más bien, auscultar a un sector de la población a fin de determinar si desea pertenecer a una circunscripción territorial o a otra.

Hasta donde se ha podido tener conocimiento, no existiría en el Perú un estudio completo que dé cuenta exhaustiva del referéndum en tanto 
institución, incluyendo la normatividad mediante la cual estaría regulada dicha figura de la participación ciudadana directa. Se ha podido identificar ensayos puntuales ${ }^{1}$, así como trabajos sobre el contexto más amplio de la democracia directa, pero siempre sin entrar a fondo en su regulación ${ }^{2}$.

Por consiguiente, el presente trabajo tendrá por objeto contribuir a suplir dicha laguna mediante un análisis preliminar del conjunto de la normatividad vigente que regula los distintos supuestos de referéndum y estará divido en tres capítulos.

En el primero, se revisará sucintamente los antecedentes históricos del referéndum en el Perú. Se verá que hubo no solo intentos de convocarlo sino también de introducirlo en la constitucionalidad nacional. En el segundo, se abordará el concepto general de dicha institución, poniendo énfasis en los esfuerzos de tratadistas peruanos por dar cuenta de ella. En la tercera, finalmente, se tratará específicamente la regulación del referéndum desde la perspectiva tanto de la iniciativa ciudadana como de la iniciativa institucional.

\section{Antecedentes}

El referéndum es una forma de consulta popular que se ha puesto de moda desde algunos años. Si bien hizo su aparición con nombre propio recién con la Constitución actual, nuestra historia registra antecedentes que remontan a las postrimerías del siglo XIX.

Al término de la Guerra del Pacífico, el Perú y Chile acordaron al suscribir el Tratado de Ancón, el 20 de octubre de 1883, que las provincias de Tacna y Arica habrían de continuar en posesión de Chile durante un plazo diez años, al cabo del cual el destino final de ambas provincias habría de ser decidido mediante plebiscito —otra forma de consulta popular- es decir por sus propios habitantes.

1 Blancas Bustamante, Carlos. «El referéndum en la Constitución peruana». Elecciones, N 3. Lima: Oficina Nacional de Procesos Electorales, 2004; Maraví Sumar, Milagros. «Los mecanismos de democracia directa en el Perú». Ensayos Americanos. Buenos Aires, agosto 1995, pp. 1-13; RUBio CoRreA, Marcial. «La discusión pendiente sobre el referéndum». lus et Veritas. Lima. Año 4, No 7, noviembre 1993, pp. 175-179.

2 Miró Quesada Rada, Francisco. Democracia directa y Derecho Constitucional. Lima: Artes y Ciencias, 1990. 
Dicho plebiscito nunca tuvo lugar y la cuestión de Tacna y Arica fue resuelto mediante la división en dos, quedando Tacna en el Perú y Arica en Chile, de conformidad con los términos del artículo 2 del Tratado suscrito en la ciudad de Lima el 3 de junio de 1929.

Durante el año 1913, el presidente Guillermo E. Billinghurst concibió el proyecto de recurrir a la celebración de un plebiscito - otra forma de consulta popular - para reformar la Constitución de 1860, vigente en aquel entonces, con miras a que el pueblo pudiese dirimir en conflictos entre el Poder Ejecutivo y el Poder Legislativo. En vista de sus malas relaciones con el Congreso de la época, Billinghurst consideró que la única manera de llevar a cabo dichas reformas era sometiéndolas directamente a la consideración del pueblo. Una de ellas consistía, casualmente, en la implantación en el Perú del sistema de referéndum o plebiscito nacional. Billinghurst fue depuesto por el coronel Oscar R. Benavides el 4 de febrero de 1914, antes de que tales reformas pudieran ser propuestas a la población.

Apenas un lustro más tarde, Augusto B. Leguía tuvo más suerte que Billinghurst y consiguió aprobar mediante un plebiscito los criterios que habrían de guiar la reforma constitucional que terminaría con la elaboración y promulgación de la Constitución de 1920. La iniciativa plebiscitaria de Leguía tuvo en común con la de Billinghurst en que su objeto fue reforzar el Poder Ejecutivo frente al Legislativo, pero se diferenció de aquella en que no contemplaba en modo alguno la introducción de la consulta popular en la Constitución. Por otro lado, no deja de ser interesante recordar que hubo una propuesta en la Asamblea Nacional para que la Constitución de 1920 fuese sometida a la consideración del pueblo, pero no fue aceptada.

En 1939, siendo Presidente de la República, el general Benavides —el mismo militar que derrocara en 1914 a Billinghurst - consiguió que se apruebe mediante un plebiscito una serie de reformas a la Constitución de 1933. Es cierto que tales reformas tampoco tuvieron como finalidad la introducción de la consulta popular en la Constitución, pero no deja de ser irónico que Benavides recurriera al mismo procedimiento que motivara su golpe de Estado un cuarto de siglo antes. Las reformas de Benavides sobrevivieron un período legislativo completo —entre 1939 y 1945 - hasta su anulación por el Congreso durante el gobierno de José Luis Bustamante y 
Rivero. El argumento esgrimido fue que el plebiscito había sido realizado fuera del régimen constitucional.

Paralelamente, cabe ser puesto en relieve que las consultas populares no fueron solo un recurso político que se llevó —o se trató de llevar- a la práctica en circunstancias determinadas, como se acaba de ver, sino que hubo intentos de introducir la figura de la consulta popular en la constitucionalidad peruana en los dos ejercicios constituyentes anteriores a la Constitución actual. Los hubo en el seno del Congreso Constituyente que confeccionó la Carta de 1933, pero sin éxito debido a que primó el criterio según el cual el grado de adelanto político de nuestra ciudadanía no permitía la práctica de formas de democracia directa.

También los hubo durante los debates en la Asamblea Constituyente de 1978, esta vez con más éxito, aunque extremadamente modesto, ya que ni siquiera se obtuvo que el término «referéndum» en sí figurara en el texto constitucional. A duras penas se consiguió que la aprobación de las modificaciones en la demarcación regional tuviera como requisito el pronunciamiento previo y directo de las poblaciones afectadas.

En la Constitución de 1993, la situación es diametralmente opuesta, aunque no, por cierto, debido a una vocación genuinamente democrática del régimen del Ing. Fujimori. El referéndum no solo aparece con todas sus letras sino que pasa a constituir, al mismo tiempo, un derecho fundamental, un derecho político y un derecho colectivo. Por otro lado, aparece también como una opción del Congreso de la República en materia de reformas constitucionales.

No obstante estos importantes cambios, hasta la fecha el referéndum no ha sido utilizado en relación con ninguna reforma constitucional, norma con rango de ley u ordenanza municipal. Ni siquiera el referéndum de ratificación de dicha Constitución fue convocado al amparo de sus propias disposiciones, ya que estas, como es obvio, entraron en vigor recién después del referéndum ${ }^{3}$.

3 Curiosamente, Miró Quesada Rada ha señalado que «este referéndum se realizó en estricta aplicación de la Décimo Cuarta Disposición Transitoria» de la Carta aludida. Ver Miró Quesada Rada, Francisco. Ob. cit., p. 155. 
El 4 de octubre de 2004, la Comisión de Relaciones Exteriores del Congreso de la República recomendó al Pleno la aprobación del proyecto de Resolución Legislativa 813-2001-CR, mediante la cual se autorizaba la adhesión del Perú a la Convención de las Naciones Unidas sobre el Derecho del Mar, pero supeditada a la realización de un referéndum durante las elecciones generales de 2006. Dicha consulta no tuvo lugar.

Los primeros referendos en la historia peruana a ser realizados en un régimen constitucional han sido las consultas populares regionales del 30 de octubre de 2004. Pero por iniciativa de la ciudadanía no se ha celebrado aún ninguno. Hubo dos iniciativas frustradas por intervención del Congreso de la República en la década de 1990 la primera a cargo de un grupo de trabajadores de Petroperú a efecto de someter a referéndum la privatización de dicha compañía ${ }^{4}$ y la segunda destinada a someter a consulta popular la ley de reelección presidencial ${ }^{5}$.

En marzo de 2002, la Asociación Nacional de Fonavistas (ANF) inició la recolección de firmas para solicitar que se convoque a referéndum el proyecto de ley titulado «Ley de devolución de dinero de los aportes al FONAVI a los trabajadores que contribuyeron al mismo». En junio de 2006, el Jurado Nacional de Elecciones (JNE) declaró la improcedencia de dicha solicitud, argumentando que los aportes en cuestión constituían tributos y que el artículo 32 de la Constitución prohíbe que normas de carácter tributario puedan ser sometidas a referéndum ${ }^{6}$. En septiembre de este año, el Tribunal Constitucional declaró la nulidad de la citada Resolución del

4 La Ley 26300 - Ley de los Derechos de Participación y Control Ciudadanos fue modificada dos veces, hallándose ya en curso la recolección de firmas correspondiente, mediante las Leyes 26592 y 26670 , de abril y octubre de 1996, respectivamente, que condicionaban la realización de un referéndum a la desaprobación previa por el Congreso de una iniciativa legislativa sobre la materia en cuestión, pero siempre y cuando ésa hubiera contado con el voto favorable de por lo menos 48 Congresistas. Para un análisis de ambas normas modificatorias, ver DeLGADo SILVA, Ángel. «Proceso al referéndum: entre el Congreso y el Jurado Nacional de Elecciones». En Otarola Peñaranda, Alberto (coordinador). Reelección presidencial y derecho de referéndum. Lima: Foro Democrático, 1997.

5 La iniciativa legislativa correspondiente, promovida por el Foro Democrático, fue rechazada por el Congreso en agosto de 1998 por 67 votos y sin alcanzar los 48 votos necesarios para que proceda la convocatoria a referéndum.

6 Resolución N. ${ }^{\circ}$ 1215-2006-JNE, de fecha 7 de junio de 2006. 
JNE, quedando así expedito el camino de la ANF para someter a consulta popular la devolución de sus aportes. ${ }^{7}$

Y hasta donde se tiene conocimiento, un proceso de recolección de firmas para someter a consulta popular la posibilidad de convocar a una Asamblea Constituyente estaría aún en curso.

\section{Concepto general}

El término referéndum proviene de la expresión latina ad referendum, usada según el tratadista francés Jean-Marie Denquin en el ámbito diplomático para designar un acuerdo concluido por un agente bajo reserva de ratificación. A priori, subraya Denquin, dicha fórmula no implicaba necesariamente que tal ratificación fuese una decisión tomada por el pueblo. Por el contrario, la expresión ad referendum ha sido empleada con frecuencia en casos en que la autoridad competente para efectuar la ratificación no era, precisamente, el conjunto de ciudadanos. Tal era el caso en la antigua confederación helvética: los delegados a la Dieta no podían tomar decisiones sino sujetas a la ratificación de quienes los enviaban. A veces se trataba del pueblo mismo, como en el caso de los «Landsgemeinden», pero en otros se trataba de «burguesías» o Consejos soberanos ${ }^{8}$.

Aún hoy en día, los tratados sujetos a ratificación, es decir que no entran en vigor al momento de su suscripción sino cuando las partes contratantes se comunican entre ellas que han cumplido con sus respectivos procedimientos internos, no son otra cosa que acuerdos concertados ad referendum, solo que en estos casos la ratificación no es efectuada mediante una consulta popular sino mediante una decisión del órgano legislativo.

Con el paso del tiempo, la expresión ad referendum se redujo a simplemente referéndum y pasó a significar no solo el acto mediante el cual se producía la ratificación, sino además un cierto tipo de acto: una consulta al cuerpo electoral. En tal sentido, vale la pena poner en relieve que el concepto de referéndum sugiere ab initio el contexto de una forma de gobierno en la cual las decisiones que deberán ser objeto de una ratificación

Exp. N. ${ }^{\circ}$ 01078-2007-PA/TC, de fecha 3 de septiembre de 2007.

8 Denquin, Jean-Marie. Référendum et Plébiscite. Paris: Librairie Générale de Droit et de Jurisprudence, 1976, p. 4. 
son tomadas por órganos representativos, puesto que de otro modo no se explicaría la necesidad de tal ratificación. En efecto, si la ratificación tiene que tener lugar en todos los casos ya no sería ratificación sino simple y llanamente aprobación. Por ello, el referéndum parece más una figura de la democracia representativa que de la directa. En esta última, el pueblo delibera y aprueba de manera directa y sin intermediarios que aprueben preliminarmente.

Este cambio de significado puede ser apreciado en las definiciones contemporáneas del referéndum. Así, Manuel García Pelayo define el referéndum como el «derecho del cuerpo electoral a aprobar o a rechazar las decisiones de las autoridades legislativas ordinarias». Añade dicho tratadista que puede ser de las siguientes clases:

I. Por su fundamento jurídico: a) Obligatorio, cuando es impuesto por la constitución como requisito necesario para la validez de determinadas normas legislativas. B) Facultativo, cuando su iniciativa depende de una autoridad competente para ello, por ejemplo, de una determinada fracción del cuerpo electoral o de las Cámaras, o del jefe del Estado. II. Por su eficacia jurídica: a) De ratificación o sanción, cuando la norma en cuestión solo se convierte en ley por la previa aprobación del cuerpo electoral, que viene a sustituir así a la autoridad sancionadora de las leyes (ordinariamente, el jefe del Estado). B) Consultivo, cuando el resultado del referéndum no tiene carácter vinculante para las autoridades legislativas ordinarias. ${ }^{?}$

Por su parte, el jurista austriaco Hans Kelsen define el referéndum como una «forma de combinación de la democracia directa y la democracia indirecta, [...] de acuerdo con la cual ciertos proyectos aprobados por el parlamento tienen que ser sometidos al voto popular, para obtener fuerza de ley» ${ }^{10}$. Coincidiendo con ambos, Karl Loewenstein lo califica, además, como «instrumento de control político». ${ }^{11}$

9 García Pelayo, Manuel. Derecho Constitucional Comparado. Madrid: Alianza Editorial, 2000, p. 183.

10 Kelsen, Hans. Teoría General del Derecho y del Estado. México: Imprenta Universitaria, 1949, p. 314.

11 LoeWEnstein, Karl. Teoría de la Constitución. Segunda edición. Barcelona: Editorial Ariel, 1979, p. 328. 
En el Perú, el jurista Carlos Blancas Bustamante ha definido el referéndum como «votaciones populares desprovistas de carácter electoral $»^{12}$ y propuesto una tipología sobre la base de seis criterios: 1) fundamento jurídico o «necesidad» jurídica, 2) materia, 3) eficacia jurídica, 4) tiempo de realización, 5) origen y 6) ámbito territorial. ${ }^{13}$

Por su fundamento jurídico, el referéndum puede ser obligatorio cuando su realización es requisito o condición para la validez de las normas jurídicas, o facultativo, cuando no lo es.

Por su materia, puede ser constitucional, cuando versa sobre una norma de dicho carácter, o legislativo, cuando versa sobre normas con rango de ley. Los referendos constitucionales pueden ser, a su vez, autónomos, si la consulta es realizada sin la aprobación previa de una asamblea, o integrativos, cuando la consulta se integra a un proceso más amplio que incluye la participación de una asamblea. En este último caso, la consulta puede tener lugar antes o después de las deliberaciones de la asamblea elegida para tal efecto, en cuyo caso se tratará de una consulta programática o deliberativa, respectivamente. Los referendos legislativos, por otro lado, pueden ser abiertos, cuando cualquier materia puede ser sometida a consulta popular, o restringidos, cuando solo algunas pueden serlo. En este último caso, se puede distinguir entre circunscritos, cuando la Constitución señala qué materias pueden ser sometidas a consulta, y excluyentes, cuando se señala, por el contrario, qué materias no pueden serlo.

Por su eficacia jurídica, el referéndum puede ser vinculante, cuando produce efectos obligatorios, o consultivo, cuando no produce tales efectos y tiene un valor más bien político. En el primer caso, puede ser constitutivo o abrogatorio, dependiendo si su efecto es «otorgar eficacia» a norma jurídica o, más bien, «eliminar del ordenamiento jurídico una norma vigente». Entre los referendos constitutivos se puede distinguir entre ratificatorios, cuando el objeto de la consulta es «ratificar una norma previamente aprobada por el órgano legislativo» e innovativos, cuando la consulta «se crea una nueva norma con base en la iniciativa popular, sin su previa deliberación o sanción por un cuerpo legislativo».

\footnotetext{
12 Blancas Bustamante, Carlos. «El referéndum en la Constitución peruana». Elecciones, N 3. Lima: Oficina Nacional de Procesos Electorales, 2004, p. 195.

13 lb., p. 199.
} 
Por el momento u oportunidad de su realización, el referéndum puede ser sucesivo, si tiene lugar «después de la formulación o aprobación de una norma» o previo —o programático- si, por el contrario, tiene lugar «antes de la creación jurídica de la norma».

Por su origen, puede ser institucional, si la convocatoria a un referéndum es "facultad exclusiva de una autoridad o institución pública», o popular si aquella se da «por iniciativa popular a petición de una fracción del electorado».

Finalmente, el referéndum puede ser también clasificado según la extensión del ámbito territorial en el que tiene lugar, pudiendo distinguirse entre nacional, cuando tiene por objeto normas de ámbito nacional, es decir, normas con rango de ley, y subnacional, cuando tales normas tienen alcance menor al nacional (regional y local) ${ }^{14}$.

Sobre la base de esta tipología, Blancas Bustamante ha caracterizado al referéndum en el Perú como esencialmente facultativo, pues es tanto un derecho ciudadano como una atribución opcional del Congreso de la República en materia de reforma constitucional, si bien es obligatorio en relación con el proceso de descentralización. En este último caso, los referendos solo tendrán lugar durante el proceso de creación de las macroregiones y su posibilidad de su convocatoria desaparecerá una vez concluido dicho proceso.

En cuanto a su materia, el referéndum puede ser tanto constitucional como legislativo, siendo solo integrativo y sucesivo (deliberativo) en el primer caso, y restringido y excluyente en el segundo. En cuanto a su eficacia jurídica, dicha consulta será siempre vinculante, pudiendo ser indistintamente constitutivo o abrogatorio. Los referendos constitutivos pueden ser, a su vez, ratificatorios o innovativos.

Más aún, un referéndum en nuestro país será siempre sucesivo y podrá ser convocado a iniciativa institucional en materia de reforma constitucional - y en materias de descentralización mientras dure el proceso de creación de las macroregiones-, o a iniciativa popular en materia de reforma constitucional, aprobación de normas con rango de ley, ordenanzas municipales

14 lb., pp. 199-208. 
y descentralización. Finalmente, nuestro ordenamiento autoriza referendos de alcance tanto nacional como subnacional ${ }^{15}$.

\section{Regulación}

En el Perú, el referéndum es esencialmente un derecho de la ciudadanía, aunque puede ser también convocado a iniciativa del Congreso de la República en el marco de una reforma constitucional, así como por intervención del Poder Ejecutivo en el proceso de conformación de regiones en el contexto más amplio de la descentralización.

Sin embargo, este último supuesto no es comparable a los dos primeros, puesto que no se trata de una atribución permanente del Poder Ejecutivo sino de una simple función temporal que desaparecerá una vez concluida la conformación de regiones.

Así, el referéndum por iniciativa ciudadana está regulado por tres normas principales a saber: la Constitución Política, la Ley Orgánica de Elecciones $^{16}$ y la Ley de Derechos de Participación y Control Ciudadanos ${ }^{17}$.

En cuanto al referéndum convocado a instancia del Poder Ejecutivo, conviene mencionar la Ley Orgánica de Municipalidades ${ }^{18}$, la Ley de Bases de la Descentralización ${ }^{19}$, la Ley de Incentivos para la Integración y Conformación de Regiones ${ }^{20}$, así como el Reglamento del Congreso de la República.

\subsection{REFERÉNDUM POR INICIATIVA CIUDADANA}

En este acápite se analizará, en primer lugar, las disposiciones generales que son aplicables a todo referéndum convocado por iniciativa ciudadana. En segundo lugar, se analizará los distintos supuestos en los cuales un referéndum puede ser solicitado por la ciudadanía.

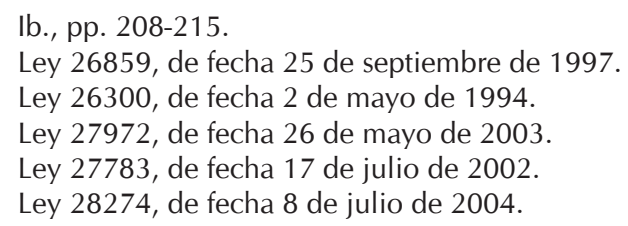




\subsubsection{Disposiciones generales}

\section{Constitución Política}

El punto de partida del derecho de los ciudadanos en relación con el referéndum es el inciso diecisiete del artículo 2 de la Constitución en vigor:

Artículo 2.- Toda persona tiene derecho: [...]

17.- A participar, en forma individual o asociada, en la vida política, económica, social y cultural de la Nación. Los ciudadanos tienen, conforme a ley, los derechos de elección, de remoción o revocación de autoridades, de iniciativa legislativa y de referéndum. [...] (énfasis

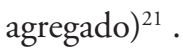

Mediante esta disposición no solo se incorpora en la constitucionalidad peruana varios mecanismos de participación directa de la ciudadanía - revocación de autoridades, iniciativa legislativa y referéndum- sino que se les incorpora con el rango de derechos fundamentales, tal como se infiere de su ubicación en el capítulo constitucional que enuncia los derechos fundamentales de la persona, criterio que sido confirmado por el Tribunal Constitucional ${ }^{22}$.

Estos derechos fundamentales aparecen nuevamente en otro capítulo del mismo Título. Se trata del Capítulo III, denominado «De los derechos políticos y deberes» y cuyo objeto es hacer referencia específica a los derechos políticos y deberes de la ciudadanía.

Artículo 31.- Los ciudadanos tienen derecho a participar en los asuntos públicos mediante referéndum; iniciativa legislativa; remoción o revocación de autoridades y demanda de rendición de cuentas. Tienen también el derecho de ser elegidos y de elegir libremente a sus representantes, de acuerdo con las condiciones y procedimientos determinados por ley orgánica. [...]

Nótese que la denominación de este capítulo se limita a consignar «De los derechos políticos y deberes» pero sin precisar que los titulares de tales derechos y deberes son los ciudadanos. Sin embargo, la ubicación de este capítulo dentro del título relativo a la persona y la sociedad sugiere ab initio que solo podría tratarse de los derechos políticos y deberes de los ciudadanos.

21 Salvo indicación en contrario, todos los subrayados y enfásis son agregados.

22 Exp. 0003-1999-Al/TC, Fundamento jurídico 1. 
Por otro lado, se trata de derechos fundamentales sujetos a desarrollo legislativo, tal como se desprende de la formulación misma de la disposición constitucional. En tal sentido, los derechos de iniciativa legislativa, iniciativa de reforma constitucional, revocatoria y remoción de autoridades, y referéndum, así como de demanda de rendición de cuentas, que no figura en el artículo 2 sino en el 31 de la Constitución, están regulados por la Ley de los Derechos de Participación y Control Ciudadanos ${ }^{23}$. El derecho de elección, en cambio, está regulado por la Ley Orgánica de Elecciones ${ }^{24}$.

Ahora bien, conviene notar que el derecho de referéndum está formulado en términos de un medio para canalizar la participación de los ciudadanos en los asuntos públicos de la sociedad. Esta formulación resulta de la mayor importancia, ya que no se trata del derecho de los ciudadanos a participar en un referéndum sino a participar en los asuntos públicos mediante el referéndum.

Esta distinción no es formal sino sustantiva. En el primer caso se trataría de un derecho de carácter pasivo: si se convoca a un referéndum, los ciudadanos estarían facultados para participar en él, lo que constituye una interpretación más bien carente de sentido en un país en el que el voto es obligatorio. Pero en el segundo, se trataría más bien de un derecho de carácter activo: pues implica que los ciudadanos están investidos del derecho a provocar la ocurrencia de un referéndum con el objeto de hacer sentir su parecer en el ámbito de los asuntos públicos.

Más aún, no obstante que el legislador ha recibido el mandato de regular legalmente el ejercicio del derecho de referéndum, tal como consta en el inciso 17 del artículo constitucional 2, el constituyente ha considerado conveniente orientar la labor de aquel fijando en el propio texto constitucional las materias susceptibles de ser sometidas a referéndum así como aquellas que no podían serlo. Este es el sentido del artículo 32:

Artículo 32.- Pueden ser sometidas a referéndum:

1. La reforma total o parcial de la Constitución;

2. La aprobación de normas con rango de ley;

3. Las ordenanzas municipales; y

4. Las materias relativas al proceso de descentralización.

23 Ley 26300, del 2 de mayo de 1994.

24 Ley 26859, del 25 de septiembre de 1997. 
No pueden someterse a referéndum la supresión o la disminución de los derechos fundamentales de la persona, ni las normas de carácter tributario y presupuestal, ni los tratados internacionales en vigor.

La orientación seńalada constituye al mismo tiempo una garantía constitucional ante eventuales intentos excesivamente restrictivos de parte del legislador, quien no podría proceder sin tener en cuenta este artículo constitucional. Asimismo, esta interpretación sugiere la conveniencia de matizar la tesis según la cual el derecho de los ciudadanos a convocar un referéndum no estaría plenamente garantizado, tal como ha sido sugerido ${ }^{25}$.

Finalmente, y antes de pasar a examinar la regulación de estos cuatro supuestos, conviene poner en relieve el criterio expuesto al inicio del presente acápite y según el cual las disposiciones de este artículo no tienen por objeto constituir preceptos de orden general y abstracto sino habilitaciones y limitaciones dirigidas exclusivamente a los ciudadanos.

Este punto es importante en la medida en que se ha sugerido que la prohibición de someter determinadas materias a referéndum señalada el término del artículo 32 constituiría una prohibición de carácter abstracto y general $^{26}$. Sin embargo, si se admite la validez del razonamiento según el cual el objeto de los diversos artículos que componen el Capítulo III del primer Título de la Constitución es la regulación de los derechos políticos y deberes de los ciudadanos, se deberá también admitir que las prohibiciones señaladas en el último párrafo del artículo 32 solo podrían afectar a los ciudadanos ${ }^{27}$.

\section{Ley Orgánica de Elecciones (LOE)}

Entre las disposiciones de carácter general aplicables al referéndum por iniciativa ciudadana que se encuentran en la LOE conviene poner en relieve

25 Cfr. Maraví Sumar, Milagros. «Instituciones de democracia directa en Perú». En Martín Krause y Margarita MoltenI (coordinadores). Democracia directa. Buenos Aires: Abeledo-Perrot. 1997, p. 134.

26 Bernales Ballesteros, Enrique, con la colaboración de Alberto Otarola, La Constitución de 1993. Análisis comparado. Quinta edición. Lima: Editora Rao, 1999, p. 275.

27 Es curioso constatar que el mismo artículo 32 faculte a los ciudadanos a someter, aunque no directamente, un proyecto de reforma total de la Constitución, pero les prohíba al mismo tiempo someter a referéndum temas puntuales como derechos humanos, asuntos tributarios y tratados internacionales. Esto parecería ser una contradicción puesto que una reforma total debería poder abarcar todos los aspectos de la Constitución. 
en primer lugar al artículo 6, que señala expresamente al referéndum como uno de los procesos electorales comprendidos en dicha ley.

Pero quizá más importante aún es que dicho artículo define al referéndum como una consulta popular cuyo objeto es «convalidar o rechazar determinados actos de gobierno", motivo por el cual ha de tener carácter mandatorio. Dispone asimismo que puede ser requerido tanto por el Estado como por iniciativa popular. En este último caso, agrega dicha disposición, la iniciativa procede de acuerdo con las normas y los principios de Participación Ciudadana, en alusión inequívoca a la Ley de Derechos de Participación y Control Ciudadanos.

Una segunda disposición de carácter general se encuentra en el segundo párrafo del artículo 82, que fija el plazo para la convocatoria a un referéndum. Según este, dicha convocatoria se hace con una anticipación no mayor de 90 (noventa) días naturales ni menor de 60 (sesenta).

Una tercera tiene que ver con el Decreto de Convocatoria a referéndum. Se trata del artículo 83, que está referido a todos los procesos electorales comprendidos en esta ley, y según el cual resulta imperativo que todo Decreto de Convocatoria especifique lo siguiente: a) el objeto del proceso; b) fecha de su realización; c) tema o temas por consultar; d) circunscripciones electorales en que tendrá lugar; y e) autorización del Presupuesto.

Por otro lado, la LOE recoge las mismas habilitaciones y restricciones al referéndum por iniciativa ciudadana que aquellas consignadas en el artículo 32 de la Constitución. Se trata de los artículos 125 y 126 del Capítulo 5 del Título V de la LOE:

\section{De las consultas populares}

Artículo 125.- Pueden ser sometidos a referéndum:

a) La reforma total o parcial de la Constitución;

b) La aprobación de normas con rango de ley;

c) Las ordenanzas municipales; y

d) Las materias relativas al proceso de descentralización.

Artículo 126.- No pueden ser sujeto de consulta popular:

a) Los temas relacionados con la supresión o disminución de los derechos fundamentales de la persona.

b) Normas de carácter tributario o presupuestal.

c) Tratados internacionales en vigor. 
Nótese que estos artículos deben ser leídos en estricta concordancia con el citado artículo constitucional 32, ya en este último caso no queda duda alguna, en razón de su ubicación, que sus disposiciones se refieren exclusivamente a los derechos de los ciudadanos, mientras que, en el caso de la Ley Orgánica de Elecciones, se podría pensar inadvertidamente que se trata de una disposición de orden general sobre el referéndum y no referida solo a los derechos de la ciudadanía. Esto se debe a que el Capítulo 5 en comentario forma parte del Título V, cuyo objeto es regular todo lo relativo a las inscripciones y candidatos, motivo por el cual no parece haber sido el lugar más apropiado para ubicar los temas susceptibles de ser sometidos a consulta popular.

\section{Ley de Derechos de Participación y Control Ciudadanos (LDPCC)}

Entre las disposiciones generales sobre el referéndum ubicadas en la LDPCC cabría resaltar en primer lugar su artículo 2, que recoge expresamente el derecho consagrado en el inciso 17 del artículo constitucional segundo, al caracterizar al referéndum como uno de los derechos de participación ciudadana.

Las siguientes disposiciones generales que conviene mencionar se encuentran en los artículos 37, 38, 39, 40 y 42 del Capítulo V de esta ley y que se titula «Del referéndum y de las consultas populares».

En virtud del artículo 37, el referéndum es definido como el derecho de los ciudadanos para pronunciarse conforme a la Constitución en los temas normativos que se le consultan. Nótese que esta disposición complementa la definición dada en el artículo 6 de la Ley Orgánica de Elecciones, según la cual el objeto de dicha consulta popular era "convalidar o rechazar determinados actos de gobierno». Así, se debe entender que tales «actos de gobierno» son los «temas normativos» a que hace alusión el artículo 37 en comentario.

Una segunda disposición de crucial importancia, es el artículo 42, que dispone que un referéndum surtirá efecto, ya sea para que entre en vigencia una norma aprobada o para que sea derogada una que hubiera sido desaprobada, «siempre que hayan votado en sentido favorable a la consulta la mitad más uno de los votantes, sin tener en cuenta los votos nulos o en blanco» y siempre que «fuera aprobada por no menos del $30 \%$ del número total de 
votantes». Agrega dicha disposición que el resultado del referéndum surtirá sus efectos «a partir del día siguiente de la publicación de los resultados oficiales por el Jurado Nacional de Elecciones».

Una tercera disposición de no menor importancia es el artículo 38, que señala que dicha consulta popular puede ser solicitada por un número de ciudadanos no menor al 10 por ciento del electorado nacional. Al respecto, conviene resaltar que este requisito ha sido considerado excesivo tanto por varios tratadistas nacionales sobre esta materia ${ }^{28}$.

Por otro lado, la LDPCC, al igual que la LOE, recoge las mismas habilitaciones y restricciones al referéndum por iniciativa ciudadana que aquellas consignadas en el artículo 32 de la Constitución. Se trata de los artículos 39 y 40 del Capítulo V del Título II de la LDPCC. No obstante el parecido, conviene citarlo in toto puesto que, a diferencia de su modelo constitucional, distinguen entre aprobación y desaprobación de normas con rango de ley:

Artículo 39.- Procede el referéndum en los siguientes casos:

a) La reforma total o parcial de la Constitución, de acuerdo al artículo 206 de la misma.

b) Para la aprobación de leyes, normas regionales de carácter general y ordenanzas municipales.

c) Para la desaprobación de leyes, decretos legislativos y decretos de urgencia, así como de las normas a que se refiere el inciso anterior.

d) En las materias a que se refiere el artículo 190 de la Constitución, según ley especial.

Artículo 40.- No pueden someterse a referéndum las materias y normas a que se refiere el segundo párrafo del artículo 32 de la Constitución.

Finalmente, conviene hacer mención del artículo 44, que dispone que la autoridad electoral —el Jurado Nacional de Elecciones en este casodeberá efectuar la convocatoria en un plazo no mayor de cuatro meses después de acreditadas las iniciativas respectivas.

28 Ver Blancas Bustamante, Carlos. Ob. cit., p. 215; Maraví Sumar, Milagros. Ob. cit., p. 138; y Miró Quesada Rada, Francisco. Ob. cit., p. 158. 


\subsubsection{Reforma de la Constitución}

La reforma de la Constitución está específicamente regulada por las disposiciones del Título VI de la Carta, denominado precisamente «De la reforma de la Constitución». Este Título está integrado por un solo artículo, el artículo 206, que contiene los dos procedimientos alternativos mediante los cuales la Constitución en vigor puede ser modificada.

En virtud del primero, la reforma debe ser aprobada por el Congreso por mayoría absoluta del número legal de sus miembros y ratificada mediante referéndum. Y según el segundo, el referéndum puede ser omitido si el acuerdo del Congreso se obtiene con una votación superior a los dos tercios del número legal de sus miembros en dos legislaturas ordinarias sucesivas.

Como se puede apreciar, el referéndum procede, de conformidad con este artículo constitucional, por iniciativa del Congreso de la República. Sin embargo, también es posible que la iniciativa de someter un proyecto de reforma de la Constitución provenga de la propia ciudadanía, pero en base no del artículo 206 aludido, sino de una disposición constitucional que se encuentra en el Título I de la Constitución, denominado «De la persona y la sociedad». Se trata del artículo 32, según el cual:

Artículo 32.- Pueden ser sometidas a referéndum:

1. La reforma total o parcial de la Constitución. [...]

Al respecto, conviene recordar que, tal como quedó claro en el acápite anterior, las disposiciones contenidas en los artículos que integran el Capítulo III del primer Título de la Constitución están referidos exclusivamente a los ciudadanos, lo que permite precisar que la proposición «pueden ser sometidas a referéndum» al inicio de este artículo debe ser entendida como «los ciudadanos pueden someter a referéndum ${ }^{29}$.

Más allá de recordar el artículo 38 de la LDPCC, que dispone que «el referéndum puede ser solicitado por un número de ciudadanos no menor al 10 por ciento del electorado nacional», resulta de mayor importancia notar que el inciso a) de su artículo 39 dispone expresamente que el referéndum

29 Ver acápite 3.1.1.- Disposiciones generales. 
procede para «la reforma total o parcial de la Constitución, de acuerdo al Artículo 206 de la misma» (énfasis agregado). Esto significa que la ciudadanía solo puede solicitar que se someta a referéndum un proyecto de reforma de la Constitución que hubiera sido previamente aprobado por el Congreso de la República.

La pregunta que sigue es en qué etapa de un proceso de reforma constitucional pueden los ciudadanos ejercer el derecho a solicitar un referéndum, de conformidad con el derecho previsto en el inciso 1 del artículo constitucional 32 y regulado por los artículos 38 y 39 de la Ley de los Derechos de Participación y Control Ciudadanos. Habida cuenta que el referéndum es obligatorio en el primer procedimiento del artículo 206, es decir luego de una aprobación por el Congreso por una mayoría absoluta, la única circunstancia en la que dicho derecho podría ser ejercido por la ciudadanía es en la etapa posterior a la aprobación de una reforma constitucional mediante el procedimiento de dicho artículo que permite, curiosamente, la omisión del referéndum.

Nótese que la Constitución no prohíbe la realización del referéndum si la reforma obtuvo la votación indicada en las dos legislaturas ordinarias sucesivas. Simplemente se limita a señalar que «puede omitirse» dicha consulta, lo que permite inferir que se trata de una opción abierta: tanto para el Congreso en virtud del propio artículo 206 como para los ciudadanos, pero en virtud del artículo 32.

Lo interesante de esto es resaltar que, si bien los ciudadanos no están facultados para aprobar de manera directa una reforma constitucional, en la medida en que esta debe siempre ser previamente aprobada por el Congreso, por lo menos tienen la facultad de desaprobarla en un caso de falta de sintonía flagrante entre el Congreso y la ciudadanía.

No menos interesante resulta el hecho que el artículo constitucional 32 introduce una variante en el procedimiento implícito de reforma constitucional del artículo 206: aprobación por el Congreso en dos legislaturas ordinarias sucesivas con una votación superior a los dos tercios del número legal de congresistas y ratificación —o desaprobación — por referéndum, pero a solicitud de la ciudadanía.

Queda así en evidencia que el derecho de referéndum constituye, en el contexto de un proceso de reforma constitucional, no solo un mecanismo 
de participación política directa sino además un auténtico instrumento de control ciudadano.

\subsubsection{Aprobación de normas con rango de ley}

El derecho de los ciudadanos a someter a referéndum la aprobación de normas con rango de ley es otro de los instrumentos de control político que han aparecido en el horizonte constitucional peruano a partir de la Constitución de 1993.

Este importante derecho no emana directamente del inciso $17 \mathrm{del}$ artículo 2 de la Constitución, que se limita a consagrar, entre otros, el derecho de los ciudadanos a participar en los asuntos públicos mediante el referéndum. Tampoco emana del artículo constitucional 31, ya que este reproduce los derechos enunciados en el artículo segundo aludido, además de incluir el derecho de demanda de rendición de cuentas. Emana, más bien, del propio artículo 32, que desarrolla los preceptos constitucionales señalados y según el cual,

Artículo 32.- Pueden ser sometidas a referéndum: [...]

2. La aprobación de normas con rango de ley. [...]

$\mathrm{Al}$ igual que el derecho a someter a referéndum la reforma total o parcial de la Constitución, este derecho constitucional está también regulado por la Ley de Derechos de Participación y Control Ciudadanos, mediante los incisos b) y c) de su artículo 39:

Artículo 39.- Procede el referéndum en los siguientes casos: [...]

b) Para la aprobación de leyes, normas regionales de carácter general y ordenanzas municipales.

c) Para la desaprobación de leyes, decretos legislativos y decretos de urgencia, así como de las normas a que se refiere el inciso anterior.

Nótese que el legislador ha distinguido entre referendos para aprobar y aquellos para desaprobar normas con rango de ley, ya que la ciudadanía también tiene derecho de iniciativa en la formación no solo de leyes sino también de dispositivos municipales y regionales, tal como lo dispone los incisos b) y d) del artículo 2 de la Ley de Derechos de Participación y Control Ciudadanos. 
En tales supuestos, los artículos 16 y 41 de dicha ley facultan a la ciudadanía a solicitar que su iniciativa sea sometida directamente a referéndum si esta hubiera sido rechazada o modificada sustancialmente por el Congreso de la República. Para tal efecto, por cierto, los promotores de la iniciativa deberán presentar el porcentaje de firmas que el artículo 38 de la misma ley exige (10 por ciento del electorado $)^{30}$.

Por otro lado, esta distinción se termina de entender si se tiene en consideración que la ciudadanía no tiene derecho de iniciativa en la formación de decretos legislativos ni de decretos de urgencia, por tratarse de normas de competencia exclusiva del Poder Ejecutivo. Y si bien no cabe aprobarlas mediante referéndum, sí procede su desaprobación mediante consulta popular a solicitud de la ciudadanía.

Finalmente, se debe mencionar que, según el artículo 43, una norma aprobada mediante referéndum no puede ser materia de modificación dentro de los dos años de su vigencia, salvo nuevo referéndum o acuerdo del Congreso en dos legislaturas con el voto de dos tercios del número legal de congresistas. Nótese que la referencia al Congreso en este caso sugiere que este artículo no se refiere a todas las normas susceptibles de ser aprobadas mediante referéndum sino solo a aquellas en las que participa dicho órgano legislativo.

No está de más notar que, en buena cuenta, una norma aprobada mediante referéndum adquiere, durante un lapso de dos años, una suerte de status de ley de reforma constitucional en virtud del citado artículo 43.

\subsubsection{Aprobación de ordenanzas municipales}

El derecho de los ciudadanos a someter a referéndum la aprobación de ordenanzas municipales emana directamente del artículo 32 de la Constitución que, como en el caso, de la aprobación de normas con rango de ley, desarrolla el derecho de referéndum, estipulado de manera general en

30 Ley de Derechos de Participación y Control Ciudadanos: Artículo 16.- El Proyecto de ley rechazado en el Congreso puede ser sometido a referéndum conforme a esta ley. Asimismo cuando los promotores juzguen que al aprobarla se le han introducido modificaciones sustanciales que desvirtúan su finalidad primigenia podrán solicitar referéndum para consultar a la ciudadanía sobre su aprobación.

Artículo 41.- Si la iniciativa legislativa fuera rechazada o modificada sustancialmente por el Congreso, conforme a esta ley se podrá solicitar iniciación del procedimiento de Referéndum, adicionando las firmas necesarias para completar el porcentaje de ley. 
los artículos constitucionales 31 y segundo, inciso 17. Según el artículo 32 aludido:

Artículo 32.- Pueden ser sometidas a referéndum: [...]

3. Las ordenanzas municipales; $y[\ldots]$

En efecto, las ordenanzas constituyen normas con rango de ley, tal como se infiere del hecho que figuren entre aquellas susceptibles de ser objeto de una acción de inconstitucionalidad, de conformidad con el numeral 4 del artículo 200 de la Constitución. Por ello, no parece haber sido necesario consignarlas en un numeral aparte para que los ciudadanos estén facultados para someter su aprobación a referéndum. Sin embargo, el constituyente parece haber preferido poner en relieve que la participación directa de la ciudadanía no se limitaba a los asuntos públicos a nivel nacional sino también a nivel local, a efecto de darle un mayor énfasis en su opción por la descentralización del país.

En tal sentido, este numeral del artículo constitucional 32 está regulado, al igual que el numeral relativo a la aprobación de normas con rango de ley de la misma disposición constitucional, por los incisos b) y c) del artículo 39 de la Ley de Derechos de Participación y Control Ciudadanos:

Artículo 39.- Procede el referéndum en los siguientes casos: [...]

b) Para la aprobación de leyes, normas regionales de carácter general y ordenanzas municipales.

c) Para la desaprobación de leyes, decretos legislativos y decretos de urgencia, así como de las normas a que se refiere el inciso anterior. [...]

Sin embargo, la regulación de este derecho no podría ser completa sin tener en cuenta la legislación aplicable a la esfera de los asuntos municipales, tal como lo dispone expresamente el artículo 7 de la Ley de Derechos de Participación y Control Ciudadanos: «el referéndum sobre normas municipales [...] será(n) regulado(s) por las leyes orgánicas que reglamenten lo referente a los Gobiernos Locales [...].

Se trata de la Ley Orgánica de Municipalidades ${ }^{31}$, que no solo consagra en el numeral tercero de su artículo 113 el derecho de referéndum como

31 Ley 27972, de 26 de mayo de 2003. 
mecanismo de participación vecinal, sino que lo desarrolla in extenso en su artículo 115:

Artículo 115.- El referéndum municipal es un instrumento de participación directa del pueblo sobre asuntos de competencia municipal, mediante el cual se pronuncia con carácter decisorio, respecto a la aprobación o desaprobación de las ordenanzas municipales, excepto aquellas de naturaleza tributaria que estén de acuerdo a ley.

El referéndum municipal es convocado por el Jurado Nacional de Elecciones a través de su instancia local o regional, a pedido del concejo municipal o de vecinos que representen no menos del $20 \%$ (veinte por ciento) del número total de electores de la provincia o el distrito, según corresponda.

El referéndum municipal se realiza dentro de los 120 días (ciento veinte) días siguientes al pedido formulado por el Concejo Municipal o por los vecinos. El Jurado Electoral fija la fecha y las autoridades políticas, militares, policiales, y las demás que sean requeridas, prestan las facilidades y su concurrencia para la realización del referéndum en condiciones de normalidad.

Para que los resultados del referéndum municipal surtan efectos legales, se requiere que hayan votado válidamente por le menos el 35\% (treinta y cinco por ciento) del total de electores de la circunscripción consultada.

El referéndum municipal obliga a concejo municipal a someterse a sus resultados y, en consecuencia, a dictar las normas necesarias para su cumplimiento. Pasados los tres ańos un mismo tema puede someterse a referéndum municipal por segunda vez.

Esta norma es elocuente de por sí. El referéndum tendrá efectos obligatorios, tanto para la aprobación como para la desaprobación de las ordenanzas; puede ser convocado a pedido directo de los vecinos siempre que estos representen a no menos del $20 \%$ del total de los electores a ser consultados; tendrá lugar dentro del período de 120 días posteriores a la solicitud de convocatoria; y deberá contar con la participación de no menos de 35\% de los vecinos para que sus resultados surtan efectos legales.

Dos puntos, sin embargo, merecen ser puestos en relieve. En primer lugar, que un referéndum municipal puede ser convocado, en el marco de esta ley, no solo a pedido directo de los vecinos, sino también a pedido del 
propio concejo municipal, lo que sugiere una iniciativa de carácter más institucional que popular.

Esto es interesante en la medida que esta atribución del concejo municipal ha sido consignada en el Título relativo a los derechos de participación y control vecinal, con lo cual se estaría mezclando de manera confusa atribuciones del concejo municipal con derechos de participación vecinal. En buena cuenta, el artículo 115 le estaría otorgando una función de control de ordenanzas al propio órgano competente para aprobarlas: el concejo municipal.

Y, en segundo lugar, cabe notar que el último párrafo del artículo 115 dispone que el concejo municipal se verá en obligación de dictar normas para el cumplimiento de los resultados de un referéndum, lo que tendría poco sentido en la medida en que los efectos de una consulta popular a nivel municipal debieran ser directos e inmediatos: aprobación o desaprobación de norma consultada. Así, la redacción de este párrafo sugiere que, en caso de haber sido una ordenanza desaprobada en un referéndum, se hará necesaria una ordenanza adicional que la derogue.

\subsubsection{Modificación de regiones}

El derecho de los ciudadanos a someter a referéndum asuntos relativos al proceso de descentralización en el país emana, así como los derechos referidos examinados hasta el momento, del artículo constitucional 32. Según este:

Artículo 32.- Pueden ser sometidas a referéndum: [...]

4. Las materias relativas al proceso de descentralización.

Así como en el caso de los tres primeros numerales del artículo constitucional citado, el derecho estipulado en este último numeral está también regulado por la Ley de Derechos de Participación y Control Ciudadanos, ${ }^{32}$ según la cual:

Artículo 39.- Procede el referéndum en los siguientes casos: [...]

d) En las materias a que se refiere el artículo 190 de la Constitución, según ley especial.

32 Ley 26300, de fecha 2 de mayo de 1994. 
Esta ley especial es la Ley 27783 - Ley de Bases de la Descentralización, que divide el proceso de conformación de regiones esencialmente en dos momentos. En primera instancia, se tiene la conformación misma de las regiones que tiene lugar a partir de la fusión de dos o más circunscripciones departamentales colindantes $y$, en segunda instancia, la eventual unión de distritos y provincias contiguas a una futura región.

En ambas instancias procede el referéndum, pero solo en la segunda por iniciativa de la población involucrada, tal como se dispone en el artículo 29 de dicha ley:

Artículo 29- Conformación de las regiones [...]

29.3. Las provincias y distritos contiguos a una futura región, podrán cambiar de circunscripción por única vez en el mismo proceso de consulta a que se refiere el numeral precedente. [...]

Estos preceptos son objeto de un desarrollo legislativo ulterior en la Ley 28274 - Ley de Incentivos para la Integración y Conformación de Regiones, que crea espacio para una mayor participación de la ciudadanía a través de partidos políticos y movimientos regionales mediante su artículo 17:

Artículo 17.- Iniciativas para la integración de provincias y distritos 17.1. El referéndum correspondiente a las provincias y distritos contiguos a una región podrá ser solicitado por: [...]

b) Los partidos políticos o movimientos Regionales debidamente inscritos, respaldados por el diez por ciento (10\%) de los ciudadanos de las provincias o distritos cuyo cambio de jurisdicción se plantea, mediante firmas debidamente verificadas por la Oficina Nacional de Procesos Electorales (ONPE).

c) El quince por ciento (15\%) de los ciudadanos de las provincias o distritos que deseen cambiar de jurisdicción, mediante firmas debidamente verificadas por la Oficina Nacional de Procesos Electorales (ONPE). [...]

Nótese que si un referéndum es solicitado directamente por la población involucrada, el mínimo de firmas necesario equivale a no menos del $15 \%$ del electorado que participaría en la consulta, pero si en dicha participación intervienen partidos políticos o movimientos regionales, el mínimo se reduce al 10\% del electorado en cuestión.

En cuanto, al número de votos favorables para que un referéndum surta efecto, se debe señalar una incongruencia entre la Ley de Bases de 
la Descentralización y aquella de Incentivos para la Integración y Conformación de Regiones, ya que mientras la primera dispone en su artículo 29.4 que esto ocurrirá cuando los votos favorables alcancen el cincuenta por ciento más uno de los electores de la circunscripción consultada, es decir, mayoría absoluta, la segunda señala en su artículo 22 que la propuesta será considerada aprobada si la consulta alcanza un resultado favorable de cincuenta por ciento más uno de los votantes que efectivamente acudieron a votar, es decir mayoría relativa.

Finalmente, no está de más hacer notar que, según el artículo 42 de la Ley de Derechos de Participación y Control Ciudadadanos, un referéndum deberá surtir efecto si la propuesta ha recibido el voto favorable de la mitad más uno de los votantes, sin tener en cuenta los votos nulos o en blanco. Como se recordará, en el referéndum realizado el 30 de octubre de 2005 para la conformación de regiones los votos nulos y blancos sífueron computados.

\subsection{REFERÉNDUM POR INICIATIVA INSTITUCIONAL}

Tal como se señaló en la caracterización del referéndum al final del capítulo sobre el concepto general del referéndum, este puede ser también convocado por iniciativa institucional: por el Congreso de la República en el marco de un proceso de reforma de la Constitución y por el Poder Ejecutivo en el proceso de conformación de regiones en el contexto de la descentralización. ${ }^{33}$

Adicionalmente, se ha podido detectar que parte del articulado de la Ley Orgánica de Municipalidades ha sido redactada de manera tal a dar pié a pensar que la convocatoria a referéndum podría producirse también a pedido de un concejo municipal. Estos son los supuestos que serán examinados a continuación.

33 Ver Sección 2.- Concepto general. 


\subsubsection{Reforma de la Constitución}

El procedimiento para reformar la Constitución Política vigente está expresamente estipulado en su Título VI, denominado precisamente «De la reforma de la Constitución». Este Título está conformado por un solo artículo, cuyo tenor es el siguiente:

Artículo 206.- Toda reforma constitucional debe ser aprobada por el Congreso con mayoría absoluta del número legal de sus miembros, y ratificada mediante referéndum. Puede omitirse el referéndum cuando el acuerdo del Congreso se obtiene en dos legislaturas ordinarias sucesivas con una votación favorable, en cada caso, superior a los dos tercios del número legal de congresistas. [...]

Conviene precisar de inmediato que tanto el nombre del Título como la redacción de su única disposición no dejan lugar a dudas sobre la supremacía jerárquica que el artículo 206 debe tener en cualquier ejercicio de modificación constitucional.

Y no podría ser de otro modo, puesto que se trata de un Título de la Constitución dedicado específicamente para tal efecto, motivo por el cual toda otra norma constitucional que pudiera estar relacionada con el proceso de modificación de la Constitución debe estar, necesariamente, sometida a lo dispuesto por aquel. Por otro lado, la redacción del artículo 206 en comentario dispone expresamente que todas las iniciativas de reforma constitucional, indistintamente de su objeto o alcance, deben ser reguladas por sus disposiciones.

En lo que al referéndum se refiere, se puede apreciar que el Congreso de la República ha sido habilitado para modificar la Constitución mediante dos procedimientos alternativos: en primer lugar, sometiendo a ratificación del pueblo mediante referéndum un proyecto de reforma que hubiera sido previamente aprobado por la mayoría absoluta del número legal de sus miembros; $y$, en segundo, omitiendo el referéndum si el proyecto de reforma hubiese sido aprobado en dos legislaturas sucesivas con una votación superior, en ambos casos, a los dos tercios del número legal de congresistas.

$\mathrm{Al}$ respecto, conviene notar que el artículo 206 dispone expresamente que el referéndum "puede ser omitido» no que «debe» serlo, con lo cual 
quedan en evidencia tres ideas: en primer lugar, que nada en dicha redacción permite inferir que el primer procedimiento pudiera estar destinado a un tipo de reforma - la total — y el segundo al otro tipo de reforma - la parcial. En segundo lugar, que el Congreso no tiene obligación alguna a optar por uno u otro procedimiento, quedando así dicha elección a la discrecionalidad de los señores congresistas y a la correlación de fuerzas políticas al momento de llevar a cabo la modificación. Y, finalmente, que el Congreso tampoco está impedido de someter un proyecto de reforma constitucional a referéndum aun cuando lo hubiese aprobado mediante el procedimiento que permite su omisión.

Finalmente, cabe señalar que las disposiciones constitucionales en comentario han sido recogidas casi ad litteram por el inciso a) del artículo 81 del Reglamento del Congreso:

Artículo 81.- Para el debate y aprobación de proposiciones de ley que no se refieran a materia común, se observarán las siguientes reglas:

a) Leyes de reforma de la Constitución; se aprobarán con el voto favorable de por lo menos la mitad más uno del número legal de Congresistas, para luego ser sometida a referéndum o, en su defecto, será aprobada en dos períodos anuales de sesiones sucesivos con el voto aprobatorio de un número superior a los dos tercios del número legal de Congresistas. [...]

Sin embargo, no se puede dejar de mencionar que el citado Reglamento no contiene disposición alguna en cuanto al procedimiento a seguir en caso que el Congreso hubiera tomado la decisión de someter un proyecto de reforma constitucional a referéndum, aunque se puede presumir que correspondería la aprobación de una resolución legislativa al respecto y su envío al Jurado Nacional de Elecciones para la convocatoria respectiva.

Igualmente es de presumirse que el referéndum no tendría lugar antes de sesenta días naturales ni después de noventa, según el artículo 82 de la Ley Orgánica de Elecciones, y que surtiría efectos en la medida en que hubieran votado a favor la mitad más uno de los votantes, de conformidad con el artículo 42 de la Ley de Derechos de Participación y Control Ciudadanos. 


\subsubsection{Conformación y modificación de regiones}

El gobierno del Perú es definido como unitario, representativo y descentralizado, de conformidad con el párrafo tercero del artículo 43 de la Constitución Política vigente. Sin embargo, la descentralización no es aún un hecho consolidado sino un proceso que se encuentra todavía en marcha. Entre los primeros pasos a dar destaca la conformación misma de las regiones como resultado de la integración de dos o más circunscripciones departamentales contiguas.

En tal sentido, la Constitución Política vigente dispone expresamente que:

Artículo 190.- [...] Mediante referéndum podrán integrarse dos o más circunscripciones departamentales contiguas para constituir una región, conforme a ley. Igual procedimiento siguen las provincias y distritos contiguos para cambiar de circunscripción regional. [...]

Como se puede apreciar, la decisión final sobre la conformación de una nueva región recae por mandato constitucional en la propia ciudadanía concernida, tal como lo dispone el artículo señalado y lo regula de manera directa tanto la Ley 27783 - Ley de Bases de la Descentralización ${ }^{34}$ como en la Ley 28274 - Ley de Incentivos para la Integración y Conformación de Regiones ${ }^{35}$.

La primera se refiere esencialmente al principio de la participación de las poblaciones involucradas para decidir en última instancias sobre la conformación de una región, al señalar que:

Artículo 29.- Conformación de las regiones

29.1. La conformación y creación de regiones requiere que se integren o fusionen dos o más circunscripciones departamentales colindantes, y que la propuesta sea aprobada por las poblaciones involucradas mediante referéndum. [...]

La segunda, en cambio, recoge el mismo principio en su artículo 15, pero contiene además —en su artículo 19- el procedimiento a seguir para asegurar la participación popular en el ejercicio y pone en evidencia que

34 Ley 27783, de fecha 17 de julio de 2002.

35 Ley 28274, de fecha 8 de julio de 2004. 
la iniciativa para que un referéndum sea convocado no recae en la propia población sino en el Poder Ejecutivo:

Artículo 19.- Resolución sobre el Expediente Técnico

19.1. El expediente técnico debe ser presentado hasta el último día hábil del mes de enero del año de la consulta por referéndum.

19.2. El Consejo Nacional de Descentralización emitirá informe aprobatorio o desaprobatorio del Expediente Técnico dentro de los treinta (30) días naturales siguientes a su presentación. En caso de que del Expediente Técnico se adviertan requisitos no cumplidos, estos deben ser señalados expresamente por el Consejo Nacional de Descentralización, teniéndose un plazo adicional de quince (15) días naturales para ser subsanados y resueltos.

19.3. La Presidencia del Consejo de Ministros emitirá las Resoluciones aprobatorias, por mérito de los Informes del Consejo Nacional de Descentralización, y los remitirá, acompañados de los respectivos Expedientes Técnicos, al Jurado Nacional de Elecciones.

Según el procedimiento estipulado en esta norma, la decisión sobre la convocatoria recae en el Consejo Nacional de Descentralización, entidad adscrita a la Presidencia del Consejo de Ministros, que tiene la responsabilidad de aprobar o no los Expedientes Técnicos que contienen la fundamentación de la viabilidad de la región propuesta. Una vez aprobado por el Consejo Nacional aludido, la Presidencia del Consejo de Ministros es la entidad a que corresponde notificar al Jurado Nacional de Elecciones para que se dé inicio al proceso de referéndum. Este deberá tener lugar, de conformidad con el artículo 20 de la misma ley, en un plazo no menor a ciento ochenta días calendarios.

Queda, pues, en evidencia que, en materia de conformación misma de las regiones, la convocatoria a referéndum será efectuada por el Jurado Nacional de Elecciones sobre la base de las Resoluciones aprobatorias remitidas por el Poder Ejecutivo. En otras palabras, por decisión institucional.

Una vez conformada una región, provincias y distritos contiguos que pertenezcan a otra región o a un departamento que no ha conformado aún una región, pueden decidir mediante referéndum su integración a la región recién conformada. Pero para tal efecto, el referéndum podrá ser convocado, no solo por la ciudadanía, tal como se ha examinado en otro acápite del 
presente trabajo, sino también por los Concejos Municipales provinciales o distritales, según corresponda.

Esta atribución de los Concejos Municipales está consignada en la Ley de Incentivos para la Integración y Conformación de Regiones:

Artículo 17.- Iniciativas para la integración de provincias y distritos

17.1. El referéndum correspondiente a las provincias y distritos contiguos a una región podrá ser solicitado por:

a) Los Alcaldes provinciales o distritales, según corresponda, con el acuerdo de los respectivos Concejos Municipales y concertados en el Consejo de Coordinación Local. [...]

Conviene notar que no se trata de una atribución de carácter permanente de los Consejos Municipales, toda vez que solo puede ser ejercida por única vez en el proceso mismo de la conformación de las regiones.

\subsubsection{Ordenanzas municipales}

La Constitución ha definido el referéndum esencialmente como un derecho de participación ciudadana directa en asuntos públicos, si bien ha autorizado expresamente su utilización en materia de reforma de la Constitución por iniciativa del Congreso de la República así como en ciertos asuntos de descentralización a través de la Presidencia del Consejo de Ministros y de los Concejos Municipales.

Pero no se puede afirmar que la Constitución incluya disposición alguna que sustente la atribución de los Concejos Municipales a someter sus propias ordenanzas a consulta popular.

Se ha podido detectar, sin embargo, que el artículo 115 de la Ley 27972 - Ley Orgánica de Municipalidades dispone expresamente que «el referéndum municipal es convocado por el Jurado Nacional de Elecciones a través de su instancia local o regional, a pedido del concejo municipal o por los vecinos» (énfasis agregado). Al respecto, no deja de llamar la atención que dicha norma no haya sido incluida en el título relativo a las atribuciones de los Concejos Municipales sino en aquel que regula los derechos de participación y control vecinal. 
En efecto, la aprobación, modificación y derogación de las ordenanzas figura en el inciso octavo del artículo 9 de la Ley Orgánica como atribución de los Concejos Municipales, sin que se señale expresamente que tal aprobación estará sujeta a una ratificación ulterior por el electorado correspondiente ni que su sometimiento a referéndum podrá quedar a discreción de dichos Concejos.

Así, la facultad de los Concejos Municipales para someter a referéndum sus propias ordenanzas aparecería como una atribución tácita y facultativa cuya única explicación plausible sería permitir que los concejos municipales puedan someter a consulta popular ordenanzas que, en opinión discrecional de dichas instancias ediles, pudieran versar sobre materias consideradas delicadas o transcendentales.

Por consiguiente, si se tiene en consideración la ausencia de un sustento constitucional, así como su ubicación en el cuerpo de la Ley Orgánica de Municipalidades, se debe inferir que se trata de una atribución que emana únicamente de una redacción defectuosa del artículo 115 de la Ley Orgánica señalada.

\section{Conclusiones}

El referéndum es esencialmente una institución de participación directa y control políticos a disposición de la ciudadanía que sigue siendo virtualmente desconocida, no obstante de ser uno de los términos que con mayor frecuencia aparece en el lenguaje político cotidiano.

El referéndum puede ser también convocado a instancia del Congreso de la República en el marco de un proceso de reforma de la Constitución, así como por el Poder Ejecutivo a efectos de la conformación de regiones en el contexto más amplio de la descentralización. En este último caso, no se trata sino de una función temporal que se extinguirá al concluir dicho proceso de conformación de regiones.

El referéndum no tiene por objeto socavar el régimen representativo sino, por el contrario, complementarlo mediante la introducción de un mecanismo de control político directo, lo que concuerda plenamente con la idea del equilibrio de poderes. 
La principal barrera que deben superar los ciudadanos para empezar a recurrir al referéndum como instrumento de participación directa en los asuntos públicos es el alto número de firmas requeridas para que proceda la iniciativa, número que equivale al 10 por ciento del electorado nacional.

Este requisito no tiene su origen en la Constitución sino en la Ley de Derechos de Participación y Control Ciudadanos, motivo por el cual nada impide que un Congreso de genuina vocación democrática modifique dicha ley de manera que el porcentaje requerido sea el mismo que para presentar iniciativas legislativas: 0,3 por ciento del electorado nacional.

Hasta el día de hoy, el referéndum no ha sido utilizado en relación con ninguna reforma constitucional, norma con rango de ley u ordenanza municipal. Los primeros referendos en la historia peruana realizados en un régimen constitucional han sido las consultas populares regionales del 30 de octubre de 2004. Pero por iniciativa de la ciudadanía no se ha celebrado aún ninguno.

Hubo dos iniciativas frustradas en la década de 1990: la primera a cargo de un grupo de trabajadores de Petroperú a efecto de someter a referéndum la privatización de dicha compañía y la segunda destinada a someter a consulta popular la ley de reelección presidencial.

El primer referéndum de la historia peruana a ser convocado por iniciativa ciudadana pudo haber tenido lugar a raíz del fallo del Tribunal Constitucional de septiembre de 2007 sobre el caso de la devolución de los aportes del FONAVI a los trabajadores que contribuyeron a dicho fondo.

El referéndum por iniciativa ciudadana no está regulado por una sola norma sino por una serie de disposiciones que se encuentran en tres normas principales. Estas son, aparte de la Constitución, la Ley Orgánica de Elecciones, la Ley de Derechos de Participación y Control Ciudadanos, y la Ley Orgánica de Municipalidades.

Cuando es convocado a instancia del Poder Ejecutivo en el proceso de conformación de regiones, resultan también aplicables la Ley de Bases de la Descentralización y la Ley de Incentivos para la Integración y Conformación de Regiones. 